\title{
A PROPOSED STATISTICAL MODEL FOR REAL ESTATE APPRAISAL APPLIED TO THE MIXED-USE HISTORICAL MASPIRO DISTRICT OF CAIRO
}

\author{
A. ABDEL ATY MOHAMED \\ Department of Architecture, Faculty of Engineering, Cairo University, Egypt.
}

\begin{abstract}
This paper introduces a new statistical methodological approach for the real estate appraisal based on the consideration of the changing purchasing power of money, by deducing an equation based mainly on all the affecting urban context variables other than the market, cost, and income approach that are currently used for that purpose. This is achieved through testing the proposed statistical model using these urban variables on one of the most important districts in downtown Cairo, Maspiro (next to Tahrir Square incorporating 1130 land lots), together with comparing its predicted values with a sample evaluated by professional real estate appraisers to ensure its validity. Maspiro district confronts the Nile River, and faces the Egyptian Union of Radio and Television Building, Ministry of Foreign Affairs, Embassy of Brazil, Embassy of Italy, and others. Accordingly, the paper finally illustrates that all theoretical approaches dealing with the real estate appraisal are subject to some defects ignoring the changing circumstances of each district and the urban planning variables that constitute its real value. They mainly depend on factors that are subject to change from time to time in accordance with the surrounding political, social, and economic circumstances. Over or underestimations may lead to economic loss and mislead the proposed developmental plans for the regions. The urban variables, on the other side, once measured for each real estate are not subject to these changes. Therefore, the research tests the validity of finding strong correlation between these variables and their real value, in the form of an equation by using statistical methods.
\end{abstract}

Keywords: mixed-use development, real estate appraisal, urban context variables, urban development, urban economics.

\section{INTRODUCTION}

The real estate industry has always been an 'information business' with high transaction costs and considerable inefficiency due to the difficulties in assessing what to do in markets where assets are heterogeneous and trading infrequent [1]. Property cycles which extend back over a century and have affected most untenanted or unsalable real estate assets, can all contribute to many financial crises [2-5].

Many theoretical approaches have presented different methodologies for the real estate appraisal. However, none of these have fully represented the real value of that real estate. This is attributed to the fact that there are too many variables affecting that value. In other means, any fixed theoretical approach would not yield any accurate values, as a result of many variations that are not taken into consideration. For example, the changing purchasing power of money, the urban context with all its variables, its location on street, elevation width, accessibility to major arterials and services, etc. These are all urban planning variables that change and affect the value of the real estate. Ignoring these variables can mislead all the developmental plans proposed for the regions aiming at urban revitalizations for the deteriorated areas.

Accordingly, the goal of this paper is to introduce a statistical methodology based on regression, that is capable of reviewing all the urban variables that can affect the appraisal of the real estate, as they represent absolute variables aside from any changing circumstances (social, economic, political, etc.) or the changing purchasing power of money that may deviate the real values from reality. This methodology is further based on other regression approaches previously proposed by others 
such as Janssen and Yang who used the regression approach to estimate the market value of a townhouse [6] and Monte Carlo simulations that were used to incorporate the uncertainty of valuation parameters by Hoesli et al. [7]. The methodology proposed by the researcher would be then applied on one of the most important districts in downtown Cairo, Maspiro, next to Tahrir Square, incorporating 1130 land lots. It confronts the Nile River, facing the Egyptian Union of Radio and Television Building, Ministry of Foreign Affairs, Embassy of Brazil, Embassy of Italy, and others. This region is one of the most distinguished areas in Greater Cairo Region. It contains many old deteriorated buildings and few modern ones. Therefore, their appraisal needs great accuracy. Errors in that case mean loss of milliards of Egyptian pounds.

The paper methodology begins by reviewing the theoretical approaches that have been introduced in the appraisal of the real estate so far. There will be a focus on the defects of these approaches. This would be followed by the presentation of the new proposed methodology and all the proposed variables for the real estate appraisal. In addition, these variables have to go through a strong statistical analysis including principal component and regression analysis to ensure the accuracy of results.

\section{DEFICIENCIES IN THEORETICAL APPROACHES FOR REAL ESTATE APPRAISAL} An appraisal is an estimate or opinion of value based on supportable evidence and approved methods [8]. It can also be defined as 'independently and impartially prepared estimate expressing an opinion of a defined value of an adequately described property as of a specific date, which is supported by the presentation and the analysis of relevant market information' [9]. This part illustrates the deficiencies in the three main theoretical approaches that were introduced in the appraisal of the real estate, including the cost approach, the market comparison approach, and the income approach [8-10].

\subsection{The market comparison approach}

This approach incorporates all the variables that can control the price in a matrix. These variables are compared with similar real estate to distinguish the difference between them. The property being evaluated has to be defined, together with those existing in the same street, besides the distance between the evaluated one and the others. This is necessary, as the site ultimately influences the value of the real estate. This matrix includes address, how far from the evaluated real estate, selling price, price/area for living, payment facilities, time of sale, site, rent or full property value, area, design and relationship to adjacent buildings, construction quality, age, condition, number of rooms, basement, whether it can be practically used, hot and cold conditioning if available, energy units (if available), garage, courtyards, swimming pool, fencing. All these variables are being compared with the real estate values surrounding the one being evaluated. This might lead to some confusion due to the large number of variables being compared, without statistical computations for these variables [10]. One of the most popular market comparisons is the gross rent multiplier (GRM), which is an economic comparison factor that relates the gross rent a property can produce to its purchase price. However, it does not allow for variations in vacancies, uncollectible rents, property taxes, maintenance, management, insurance, utilities, or reserves for replacements [9].

\subsection{The cost approach}

This approach is based on the estimation of the real estate value through the estimation of the value of the land upon which the building is located using the market comparison approach and the expenses required for its construction within the appraisal date (not within the date of its construction) [10]. 
Accordingly, its value includes the land value, the construction cost, and depreciation. As for the land value, it is being estimated by taking the land values for similar land lots, with the consideration of any constraints that may affect the price. The vacant land is being evaluated according to the rule 'best use', incorporating the best economic value, the most appropriate use, possibility of implementation, flexibility of the law. This can further be illustrated by the following. As for the land lots that are being occupied by any use, there are two cases: first, if the plot area of the building is at its maximum according to the law, but it needs some modifications to reach the best economic value, the land value would be computed by the subtraction of the value of the vacant land from the lowest value of one of two variables (the cost required to make the best use or the economic loss resulting from not using the land lot with the best use or according to similar circumstances for the land lot). Second: if the existing use of the land lot is not the 'best use', and it cannot be achieved. An example of this is a building of 3 floors that cannot be raised higher, and laws allow till 12 floors, but do not allow demolition. In this case, the land value is the least from the following: according to similar land lots or with percentage of occupation that should have been existing together with expenses needed to raise the building quality if needed or according to the economic revenue with the best use for the land lot, as compared with the existing.

As for the construction cost, it can be computed by one of two alternatives. First, the reproduction cost which is the cost needed to construct a similar building identical to the one being evaluated. Second, the replacement cost which is the cost needed to construct a new building with the same target but using materials and construction methods mostly used within the appraisal date. This can be achieved through three ways. First, areas (meter squared) representing the cost of the meter square estimated according to similar buildings and then multiplied by the meters in the building being evaluated. Second, enumeration: it depends on defining every building construction term (civil-architecture-electro mechanic: sanitary-electric-air condition-communication-computer, etc.) with quantities to be multiplied by the cost unit for each. Third, index method which depends on a coefficient representing the change (percentage) between the costs of construction within the appraisal date compared with that at the original time of construction, without taking into consideration the difference between buildings.

Finally, depreciation is defined as the loss in its value from its construction time till the time of appraisal. It can be classified into three categories. First, natural depreciation which can be either restored or not, and the value of the building would be assessed accordingly. Second, depreciation in the functional performance of the building, and whether it can be restored or not. Third, depreciation for external reasons (environmental-economic, etc.) such as a hospital that became too crowded, or building a restaurant in the ground floor. It is clear from that approach that all the estimations are mainly based on similar land lots. This may incorporate many errors, as they are generally based on personal estimations through all its stages including the estimation of the land lot value, the construction cost, and the depreciation. This is also the case in the income approach which can be explained in the following section.

\subsection{The income approach}

This approach considers the monetary returns a property can be expected to produce and converts that into a value the property should sell for if placed on the market today. This is called capitalizing the income stream [10]. All the expenses needed to make these revenues should be also computed. The net revenues are then estimated by subtracting the average interest taken on loans. Accordingly, the selling price is computed so that it is at least equal to the expenses and the interest on loans. This approach is not accurate as it ignores the purchasing power of money, and is based on personal assumptions. 
After the previous review for all the approaches used for the appraisal of the real estate, it is clear that they incorporate many problems that might affect the accuracy of the price estimation. This is attributed to the fact that they mainly depend on personal estimations, ignoring how their surrounding variables might affect each other, and without taking into consideration the purchasing power for the money that changes periodically. Therefore, there is a necessity of having more accurate approaches for the precise estimation of the property.

\section{THE EMPIRICAL STUDY}

This paper accordingly tests another statistical methodology that incorporates many new variables related to urban planning that affect the real estate appraisal with validation from real estate appraisers using the previous approaches. This would first be introduced through a theoretical study that defines all the factors that affect the land value. This is followed by the explanation of all the statistical procedures that should be carried out to reach the final appraisal model using the regression that has been extensively used for that purpose by applying all the defined variables affecting the land value on Maspiro district, supported by many other studies in this domain [11-17].

\subsection{Determining the variables to be used in the statistical analysis}

The urban planning related variables constitute the main factors that formalize the real value for the property and the real estate. Accordingly, the land uses, their interrelationships, accessibility, adjacency and nearness to services, industries, important arterials, or central business districts are main reasons in the land value appraisal. They can either raise or decrease the vitality and importance of the site for the property being assessed. The land use for the property and for those surrounding it are being affected by many other factors including: legislation, road and transportation network, the new induced services such as commercial uses (shopping centers), entertainment, educational and health facilities, and the adopted economic and administrative policies.

Since there are many factors that affect the appraisal of the real estate, that vary not only from one district to another but also from one lot to another, these variables have to be determined precisely. Accordingly, the research has proposed all the possible variables concerned with the urban context that can affect the appraisal, in an attempt to prove that this set of variables can formalize a true estimated value for the appraisal of the real estate, when compared with the values estimated by experts in this field. These variables can be listed as follows:

1. Building type, each land lot is assigned numbers from 1 to 14 according to their building type value.

2. Floor number.

3. Building condition, each land lot is assigned number from 1 to 3 according to their condition (1 for good, 2 for fair, and 3 for bad).

4. Structure, with value 1 for skeleton structure, 2 for wall bearing, 3 for mud structures.

5. Area.

6. Street width (the street width of each land lot according to its address).

7. Street value, all streets were evaluated and assigned numbers from 1 to 7 according to their vital importance in the area not the width.

8. Position on street, each land lot is assigned number from 1 to 13 according to its position on street and degree of intersection of the street it is lying on.

9. View, each land lot is assigned a percentage according to its view and context.

All these variables were measured for the 1130 land lots existing in the study area. 


\subsection{Site analysis on the district of application (Maspiro)}

The Egyptian Government is taking very serious steps toward solving the severe problems existing in downtown and in the rehabilitation of the high valued areas that suffer from bad conditions, even before the last events of the revolution that took place in Egypt on the 25th of January. These areas, despite their distinguished sites and economically valuable context, are not well developed. Instead, they suffer from very serious deteriorations.

Accordingly, in view of the rehabilitation plan for one of the most important sites lying in downtown and surrounded by three major arterials, this research would represent a full survey for the study area, together with the complete statistical classification for the land lots existing in the site, as a step forward toward their final economical appraisal.

The study area lies in down town in Kism of Beaulac surrounded by three main streets: Nile Corniche street, 26th of July street, and Galaa street as shown in Fig. 1. It extends in three sheikhat in Cairo, known by Abou Al Ella, Al Sheikh Ali, and Sharkas. Figure 1 shows the 1130 land lots that exist in the area, and upon which all the proposed variables have been measured.

It is of vital importance to have an accurate appraisal for every lot existing in the area. Any over estimations may lead to severe loss in milliards of investments, as it won't yield the expected incomes. While any underestimations will ultimately mislead the master plans proposed for the development. Therefore, an accurate model for the property estimation for each land lot is seriously needed.

\subsection{Site analysis on the district of application (Maspiro)}

This part represents the statistical analysis with all its procedures that would be carried out to estimate the final prices of the land lots. These steps include performing the factor analysis, and the cluster analysis, to compare between them for further verification of the results. These two analyses are performed to reach a categorization for the land lots in order to obtain definite groups and select from them a representative sample, and also to determine the number of land lots to be evaluated by the real estate appraisers. Multiple regression analysis would be further performed between the predicted prices for
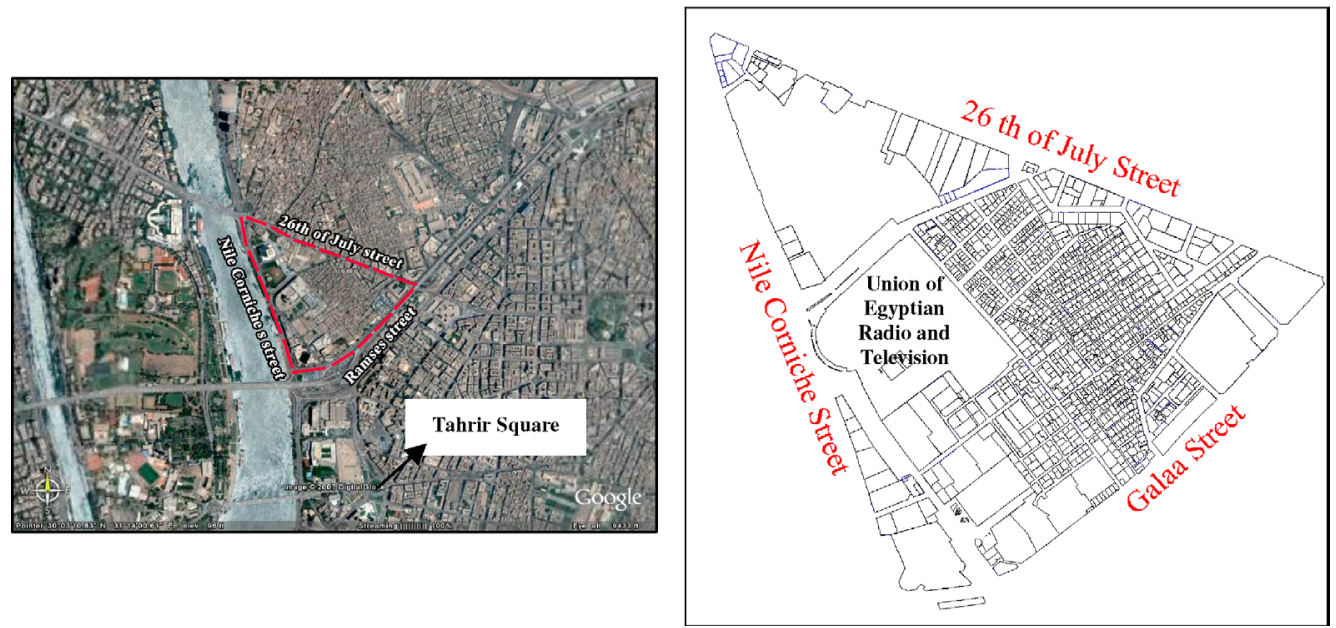

Figure 1: Study area site (Maspiro district), and the 1130 land lots surveyed in the empirical study. 
the selected sample and the most important urban variables resulting from the factor analysis, to ensure the validity of the variables in representing the prices estimated by the experts. For further validation of the equation deduced, a simple regression analysis would be performed between the factor scores of all land lots and the estimated price resulting from the equation deduced from the previous step.

\subsection{Performing the factor analysis}

In this step, all the variables are analyzed using the principal component analysis. From this analysis, it is clear that the total variance shown in Table 1 reaches $39.68 \%$, this percentage explains the percentage of variance among the first component constituting the most important variables. This component contains five main significant variables whose component loading in the component matrix reaches more than 0.5, as shown in Table 2. They are: street width, position on street, street value, view, and building type.

Table 1: Total variance explained by the factor analysis in the second run.

\begin{tabular}{|c|c|c|c|c|c|c|}
\hline \multirow[b]{2}{*}{ Component } & \multicolumn{3}{|c|}{ Initial Eigen values } & \multicolumn{3}{|c|}{ Extraction sums of squared loadings } \\
\hline & Total & $\%$ of Variance & $\begin{array}{c}\text { Cumulative } \\
\%\end{array}$ & Total & $\%$ of Variance & $\begin{array}{c}\text { Cumulative } \\
\%\end{array}$ \\
\hline 1 & 3.571 & 39.680 & 39.680 & 3.571 & 39.680 & 39.680 \\
\hline 2 & 2.654 & 29.488 & 69.168 & 2.654 & 29.488 & 69.168 \\
\hline 3 & 0.849 & 9.430 & 78.599 & & & \\
\hline 4 & 0.765 & 8.495 & 87.093 & & & \\
\hline 5 & 0.436 & 4.844 & 91.937 & & & \\
\hline 6 & 0.269 & 2.984 & 94.921 & & & \\
\hline 7 & 0.227 & 2.523 & 97.444 & & & \\
\hline 8 & 0.144 & 1.600 & 99.044 & & & \\
\hline 9 & $8.605 \mathrm{E}-02$ & 0.956 & 100.000 & & & \\
\hline
\end{tabular}

Table 2: Component matrix by the factor analysis in the second run.

\begin{tabular}{lrr}
\hline & \multicolumn{2}{c}{ Component } \\
\cline { 2 - 3 } Variables & \multicolumn{1}{c}{1} & \multicolumn{1}{c}{2} \\
\hline Street width & 0.844 & -0.346 \\
Position on street & 0.815 & -0.268 \\
Street value & -0.815 & 0.219 \\
View & 0.775 & -0.356 \\
Building type & -0.622 & -0.614 \\
Area & 0.431 & -0.307 \\
Condition & 0.231 & 0.900 \\
Structure & 0.350 & 0.896 \\
Floor no. & 0.427 & -0.134 \\
\hline
\end{tabular}


This analysis also yields the factor scores, these are number rates given to the land lots (each case) according to their importance in accordance with the measured variables. Therefore, we find that the all lots looking the Nile, 26th of July street, and Galaa street would be assigned high values. The land lots are also classified into 13 groups every 20 unit in the factor score. This would afterward be compared with the cluster analysis result to test if they match with the clusters categorized or not.

\subsection{Performing the cluster analysis}

This analysis is used to classify all the cases (land lots) into homogeneous clusters or groups according to their homogeneous characteristics (their measured variables). Therefore, all the land lots are classified into number of clusters according to their homogeneity within the variables measured. This is typically shown in the Dendrogram.

\subsection{Comparing between the factor analysis and the cluster analysis results}

By comparing between the results of the factor analysis and the cluster analysis, it was evident that the groups classified in the factor analysis match with those resulting from the cluster analysis. This implies the validity of the factor analysis to start the final selection of the categories and their number from each group that represent the land lots existing in the study area.

3.7 Determining the number and the final representative land lots samples to be selected from the groups defined in the factor analysis

This procedure was done using the graph shown in Figure 2, which defines a confidence percentage of $85 \%$ from the total samples, by selecting 62 samples from the different groups determined in the factor analysis. Therefore, a histogram, shown in Figure 3, representing the number of land lots within the factor score range is to be plotted. This helps in determining the number of samples to be selected from each group in the factor score, taking the confidence percentage $85 \%$. Table 3 shows the final land lots sample selected.

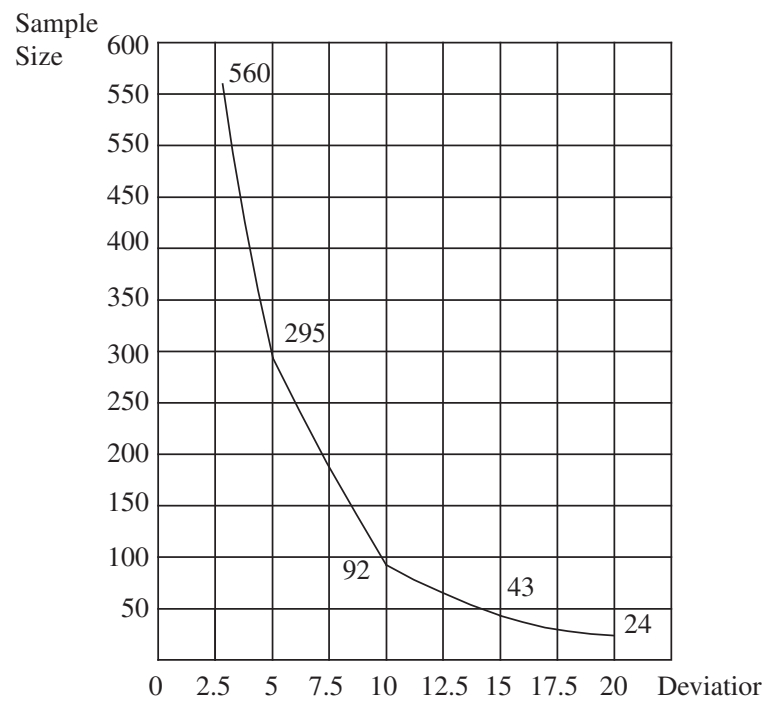

Figure 2: Deviation for the land lots sample size from the norm. 


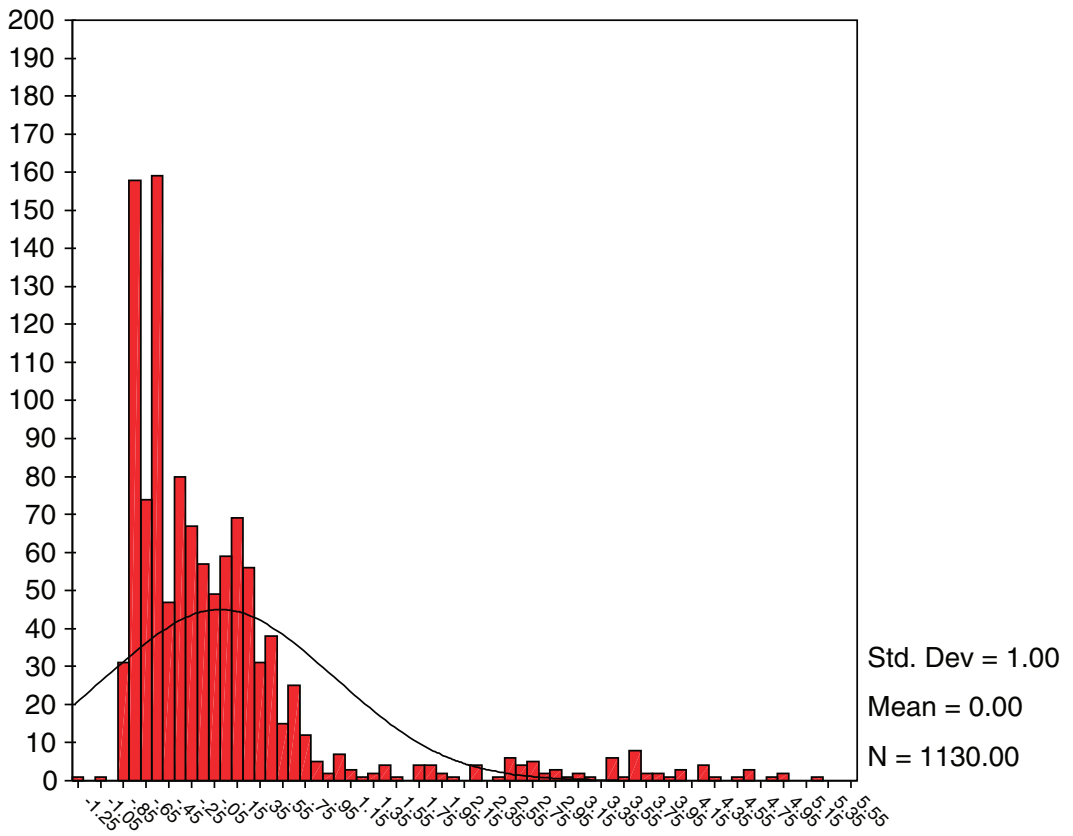

Figure 3: Histogram for the resulting factor scores for all the land lots in Maspiro district.

Table 3: The factor scores for the selected land lots sample according to the proposed categorized groups.

\begin{tabular}{lccrcc}
\hline No. & Block no. & Building no. & ID & Factor scores & Groups \\
\hline 46 & 39 & 30 & 738 & 0.42614 & 3 \\
47 & 4 & 19 & 28 & 0.47499 & 3 \\
48 & 11 & 25 & 163 & 0.58452 & 4 \\
49 & 28 & Soap factory & 631 & 0.66824 & 4 \\
50 & 26 & 10 & 621 & 0.78455 & 4 \\
51 & 7 & 34 & 98 & 1.00089 & 5 \\
52 & 28 & 4 & 637 & 1.48347 & 5 \\
53 & 40 & 106 & 756 & 1.83712 & 6 \\
54 & 27 & Vacant land & 626 & 2.29058 & 7 \\
55 & 28 & 25 & 635 & 2.7445 & 8 \\
56 & 2 & 80 & 6 & 3.47474 & 9 \\
57 & 35 & 10 & 699 & 3.62069 & 10 \\
58 & 52 & 50 & 871 & 4.28825 & 11 \\
59 & 29 & 1129 & 641 & 4.50711 & 12 \\
60 & 29 & 1119 & 647 & 4.6672 & 12 \\
61 & 29 & 1127 & 642 & 4.96993 & 12 \\
62 & 29 & 1121 & 645 & 5.24316 & 13 \\
\hline
\end{tabular}


Table 3: Continued

\begin{tabular}{lccccc}
\hline No. & Block no. & Building no. & ID & Factor scores & Groups \\
\hline 46 & 39 & 30 & 738 & 0.42614 & 3 \\
47 & 4 & 19 & 28 & 0.47499 & 3 \\
48 & 11 & 25 & 163 & 0.58452 & 4 \\
49 & 28 & Soap factory & 631 & 0.66824 & 4 \\
50 & 26 & 10 & 621 & 0.78455 & 4 \\
51 & 7 & 34 & 98 & 1.00089 & 5 \\
52 & 28 & 4 & 637 & 1.48347 & 5 \\
53 & 40 & 106 & 756 & 1.83712 & 6 \\
54 & 27 & Vacant land & 626 & 2.29058 & 7 \\
55 & 28 & 25 & 635 & 2.7445 & 8 \\
56 & 2 & 80 & 6 & 3.47474 & 9 \\
57 & 35 & 10 & 699 & 3.62069 & 10 \\
58 & 52 & 50 & 871 & 4.28825 & 11 \\
59 & 29 & 1129 & 641 & 4.50711 & 12 \\
60 & 29 & 1119 & 647 & 4.6672 & 12 \\
61 & 29 & 1127 & 642 & 4.96993 & 12 \\
62 & 29 & 1121 & 645 & 5.24316 & 13 \\
\hline
\end{tabular}

Table 4: Multiple regression analysis (model summary).

\begin{tabular}{lcccc}
\hline Model & $\mathrm{R}$ & $\mathrm{R}^{2}$ & Adjusted $\mathrm{R}^{2}$ & Standard error of the estimate \\
\hline 1 & 0.974 & 0.948 & 0.940 & 1698.211 \\
\hline
\end{tabular}

3.8 Multiple regression analysis and estimation of predicted prices equation

This analysis is performed by having the nine variables listed in the previous section act as the independent variables and the price of the selected 62 categories act as the dependent variable. The results showed high correlations existing between the prices and the variables representing the different characteristics of the land lots that reached 0.948, as shown in Table 4. This means that the deduced equation is valid for 948 cases for every 1000 cases. The equation deduced based on the coefficients in this table can be represented in eqn (1):

Price of $\mathrm{m}^{2}=(-1104.561)+(54.883 \times$ building type $)+(1118.642 \times$ floor no. $)+(34.2 \times$ condition $)$ $+(-1340.161 \times$ structure $)+(1.119 \times$ area $)+(292.795 \times$ street width $)$$$
+(385.572 \times \text { street value })+(64.141 \times \text { position on street })+(88.692 \times \text { view })
$$

In order to ensure the validity of this deduced equation, a correlation test using simple regression analysis has been performed between the prices resulting from the equation as the dependent variable and the factor scores that represent the characteristics of the land lots. The correlation was found to be 0.854 as shown in Table 6 . This is a strong correlation that validates the deduced equation and can be generalized and used for the deduction of the prices for all the other land lots existing in Maspiro district. 
Table 5: Multiple regression analysis (coefficients).

\begin{tabular}{|c|c|c|c|c|c|}
\hline & \multicolumn{2}{|c|}{ Unstandardized coefficients } & \multirow{2}{*}{$\begin{array}{c}\text { Standardized } \\
\text { coefficients } \\
\text { Beta }\end{array}$} & \multirow[b]{2}{*}{$\mathrm{t}$} & \multirow[b]{2}{*}{ Sig. } \\
\hline & B & Std. Error & & & \\
\hline (Constant) & -1104.561 & 2541.059 & & -0.435 & 0.665 \\
\hline Building type & 54.883 & 127.599 & 0.023 & 0.430 & 0.669 \\
\hline Floor no. & 1118.642 & 137.256 & 0.358 & 8.150 & 0.000 \\
\hline Condition & -34.207 & 422.234 & -0.004 & -0.081 & 0.936 \\
\hline Structure & -1340.161 & 724.544 & -0.113 & -1.850 & 0.070 \\
\hline Area & 1.119 & 0.415 & 0.107 & 2.694 & 0.009 \\
\hline Street width & 292.795 & 60.992 & 0.396 & 4.801 & 0.000 \\
\hline Street value & 385.572 & 244.697 & 0.103 & 1.576 & 0.121 \\
\hline Position on street & 64.141 & 174.862 & 0.026 & 0.367 & 0.715 \\
\hline View & 88.692 & 21.801 & 0.316 & 4.068 & 0.000 \\
\hline
\end{tabular}

Table 6: Simple regression analysis (model summary).

\begin{tabular}{lcccc}
\hline Model & $\mathrm{R}$ & $\mathrm{R}^{2}$ & Adjusted $\mathrm{R}^{2}$ & Standard error of the estimate \\
\hline 1 & 0.854 & 0.729 & 0.725 & 3636.166 \\
\hline
\end{tabular}

3.9 Defining the different price scenarios alternatives for the estimation of the final prices

Since the equation has only defined the prices according to the land lots characteristics, without taking into consideration any compensations for the residents, in case of evacuation, alternatives have been developed, in which the final price would be reduced by different proposed percentages. In the first alternative, the percentage is $0.85,0.75$ in the second alternative, 0.65 in the third alternative, and the fourth alternative would incorporate many proposed percentages according to the number of floors, and which can be listed as follows: 0.85 for vacant land, 0.75 for buildings consisting of 1 or 2 floors, and 0.65 for buildings more than 2 floors in the fourth alternative. This number in the four proposed alternatives is added to (750 Egyptian pounds $\times$ no. of floors $\times$ area of land lot) to represent the compensation fees for the residents. It is worth mentioning that the number 750 is replaced by 2000 Egyptian pounds if the land lot confronts the Nile, and 1500 Egyptian pounds if the land lot confronts Galaa street or 26th of July street, and 1000 Egyptian pounds if the land lot is near to one of the major arterials surrounding the study area. It is worth mentioning that these previous percentages and compensation numbers proposed in these alternatives are recommended by the researcher based on the investigations made during the urban survey and from meetings with the real estate appraisers, performed at the beginning of the study. The final prices for the four proposed alternatives are shown in Table 7 (only a shown sample). The final total prices for all land lots existing in Maspiro are 1454247475.6, 1388289106.0, 1256372366.9, and 1349152378.3 Egyptian pounds, respectively.

It is worth mentioning that in this study, not only the prices for the land lots were evaluated, but also the compensations for the people owning or loaning the land lots. Thirty percent of these land 


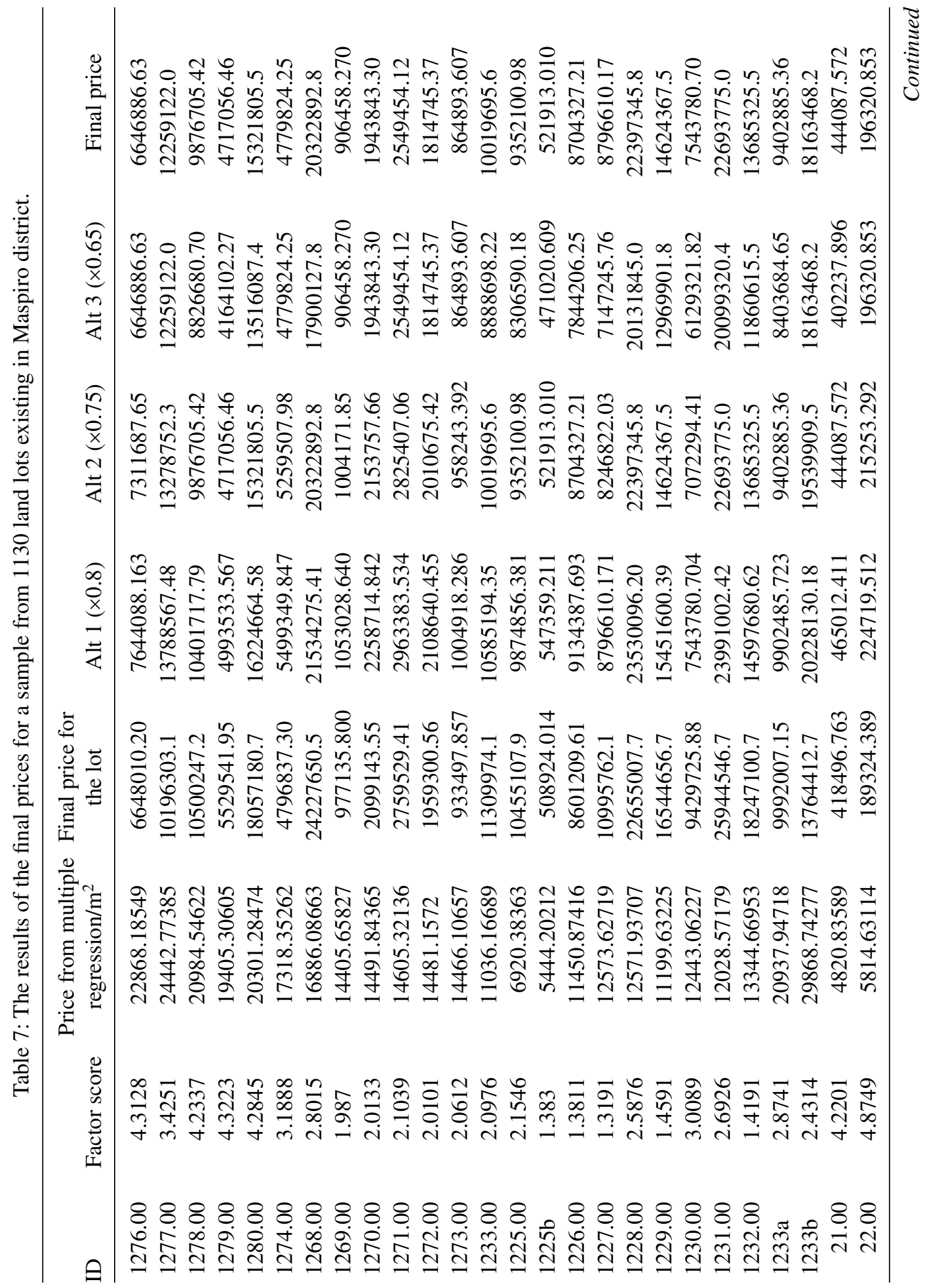




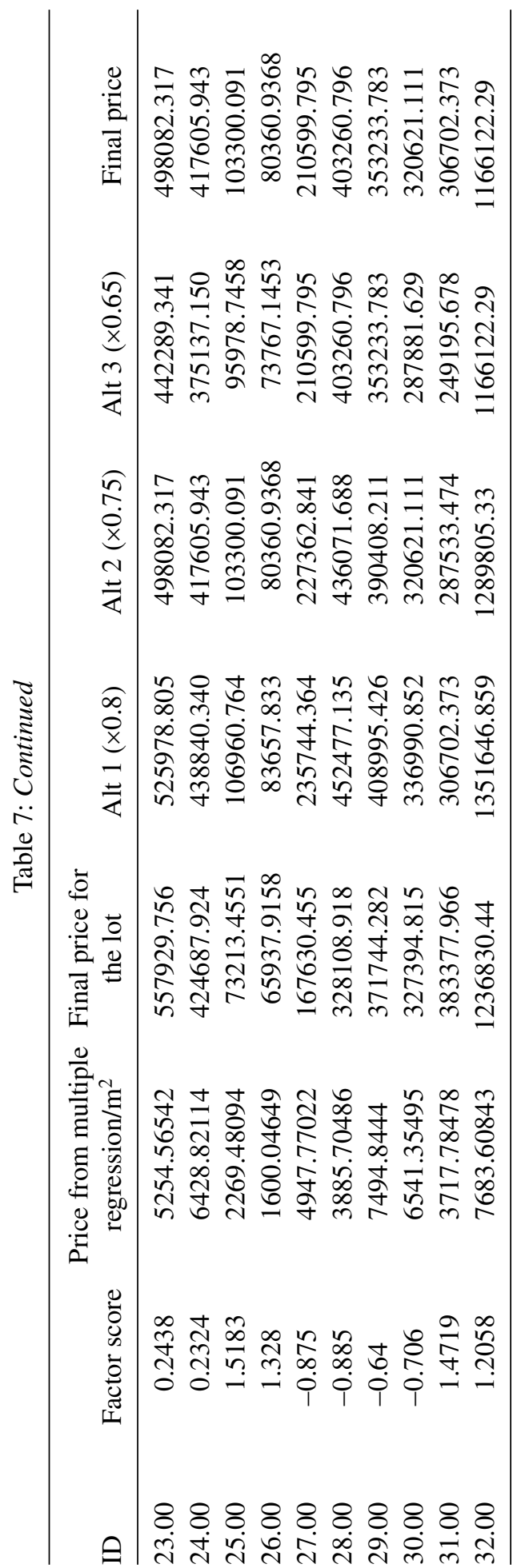


lots were sold recently within $5 \%$ more or less than the prices estimated by the study. This proves the validity of the methodology proposed by the research for the estimation of the land value and the appraisal of the real estate, depending on the urban characteristics of the land lots. This means that the methodology deduced for the estimation of the real estate value has overcome the disadvantages of the other theoretical approaches that include the changing purchasing power of money or personal estimations, and can thus be valid for all districts in all areas. As for the compensation fees, they have to be separated anyway from this procedure as they vary in accordance with the undergoing situations.

\section{CONCLUSIONS}

Since the real estate appraisal is one of the most important domains in the proposal of developmental plans especially in rehabilitation or demolition decisions, it is of vital importance to have an accurate methodology that incorporates all the urban variables that might affect their land value. During the last decades, many theoretical methodologies were used for the real estate appraisal, mainly through main three approaches including the market, cost, and income approach. However, none of these well-known approaches have succeeded in the precise representation of the real value of the real estate as a result of the existence of too many variables affecting this value that are not taken into consideration. Therefore, the research has first started with the elaboration of the deficiencies in these theoretical approaches, and then proceeded to introduce a new statistical methodological approach for the real estate appraisal, with application on the mixed-use historical Maspiro district of Cairo.

The analysis of the three common theoretical approaches revealed that they are not capable of offering adequate price estimation for the real estate, due to the main facts that they are mostly based on personal estimations, the ignorance of the changing purchasing power of money, and the negligence of all the other effective urban planning variables. These facts were clearly evident upon the review of these three approaches. First, the market comparison approach lists all variables that control the price in a matrix, which are then being compared with the real estate values. Certainly, this causes confusion due to the large number of variables compared. The cost approach is based on the estimation of the land value, the construction cost, and depreciation, upon comparison with similar land lots, depending on personal estimations. Finally, the income approach estimates the expected monetary returns produced by a property and convert it to its equivalent value if being sold on the market today. This evidently emphasizes the fact that they cannot be reliable for guiding the developmental plans, especially with the ignorance of all urban contextual variables that certainly affect the true value of the real estate.

The research has accordingly introduced a methodology including all the urban planning variables that affect the land value of the property, using a statistical model, including the context, accessibility to services and major arterials, width of elevation, etc. It has also tested their interrelationships and their vitality in causing change through a statistical model. These variables include all these ones being neglected in the main common theoretical approaches. In other means, this proposed approach has thus incorporated the statistical evaluation of these variables and how they affect each other, in the form of a deduced equation. The proposed variables concerned with the urban context included in this proposed statistical model incorporate the building type, floor number, building condition, structure, area, street width, street value, position on street, and view. These variables were measured on 1130 land lots in the mixed-use historical Maspiro district of Cairo. This district has been selected for the fact that the Egyptian Government plans the redevelopment of this deteriorated region that despite its vitality lacks any important development projects. Therefore, errors in this area mean loss 
of milliards of pounds. The statistical analysis started with performing the factor and cluster analysis to reach the categorization for the land lots to obtain a representative sample, to be evaluated by the real estate appraisers. These predicted prices and the urban variables have gone through a multiple regression analysis to reach the targeted equation. This equation was further validated by performing a simple regression analysis. Prices and compensations for residents were also estimated using the statistical model deduced. The research has thus deduced an equation that can be used afterward to be applied on every real estate being evaluated by the simple substitution of the numerical value for the variables measured for each land lot. It is worth mentioning that many of the land lots in this district were recently sold with prices that are very near from the estimated values in this research. This proves the validity of applying the deduced equation on any number of land lots in any other district. The research has thus succeeded in determining a method for real estate appraisal away from any personal estimations and respecting the changing purchasing power of money.

\section{ACKNOWLEDGEMENT}

I would like to thank Dr. Tarek Abdel Latif Aboul Atta, for giving me the opportunity to work in this research as part of a project undergone by his Planning Consultancy Office, and for his supervision throughout all the procedures of this work.

\section{REFERENCES}

[1] Smullyan, C., Kicking the Dirt at the Speed of Light. Symposium. Into the public markets: Real Estate and the New Financial Era. MIT Center for Real Estate: Cambridge. MA., 1994. Retrieved: May 28. 2003. from http://www.arctos.com/ teleres1.html.

[2] Hendershott, P. \& Kane, E., Causes and consequences of the 1980's commercial construction boom. Journal of Applied Corporate Finance, 5(1), pp. 61-70, 1994. doi: http://dx.doi. org/10.1111/j.1745-6622.1992.tb00482.x

[3] Kummerow, M.F., A system dynamics model of cyclical office oversupply. Journal of Real Estate Research, 18(1), pp. 233-255, 1999.

[4] Sterman, J. D., Business Dynamics: Systems Thinking and Modeling for a Complex World, McGraw-Hill: USA, 2000.

[5] Hanipah, B.M., Ph.D. Dissertation on the real estate's role in the Asian financial crisis. Presentation made at the Pacific Rim Real Estate Society annual meetings. Brisbane, 2003.

[6] Janssen, C. \& Yang, Z., Estimating the Market Value of a Proposed Townhouse Development. Journal of Property Investment \& Finance, 17, pp. 501-516, 1999. doi: http://dx.doi. org/10.1108/14635789910294912

[7] Hoesli, M., Jani, E. \& Bender, A., Monte Carlo simulations for real estate valuation. Journal of Property Investment \& Finance, 24, pp. 102-122, 2006. doi: http://dx.doi. org/10.1108/14635780610655076

[8] Galaty, F.W., Allaway, W.J. \& Kyle, R.C., Modern Real Estate practice, 16th edn. Dearborn Financial Publishing: U.S.A., ch. 18, pp. 300-316, 2006.

[9] Jacobus, C.J. \& Gillett, T.E., Georgia Real Estate, An Introduction to the Profession, 7th edition. Thomson Learning, Inc.: U.S.A., pp. 368-398, 2008.

[10] Fisher, D., The Commercial Real Estate Investor's Handbook: A Step-by-Step Road Map to Financial Wealth, Atlatic Publishing Group: U.S.A., pp. 63-68, 2007.

[11] Mark, J. \& Goldberg, M.A., Multiple regression analysis and mass assessment: a review of the issues. The Appraisal Journal, pp. 89-109, 1988. 
[12] Murphy, L.T III, Determining the appropriate equation in multiple regression analysis. The Appraisal Journal, pp. 498-513, 1989.

[13] Ambrose, B.W., An analysis of the factors affecting light industrial property valuation. Journal of Real Estate Research, 5(3), pp. 355-370, 1990.

[14] Fehribach, F.A., Rutherford, R.C. \& Eakin, M.E., An analysis of the determinants of industrial property valuation. The Journal of Real Estate Research, 8(3), pp. 365-376, 1993.

[15] Lasen, J.E. \& Peterson, M.L., Correcting for errors in statistical appraisal equations. The Real Estate Appraiser and Analyst, pp. 45-49, 1988.

[16] Coleman, J.W. \& Larsen, J.E., Alternative estimation techniques for linear appraisal models. The Real Estate Appraiser and Analyst, pp. 45-49, 1989.

[17] Newsome, B.A. \& Zeitz, J., Adjusting comparable sales using multiple regression analysis, the need for segmentation. The Appraisal Journal, pp. 526-532, 1992. 